\begin{abstract}
Iranica
Abstracta Iranica Revue bibliographique pour le domaine irano-aryen

Volume 37-38-39 | 2018

Comptes rendus des publications de 2014-2016
\end{abstract}

\title{
David Wilmshurst. Bar Hebraeus. The Ecclesiastical Chronicle
}

Florence Jullien

\section{OpenEdition}

1 Journals

Édition électronique

URL : http://journals.openedition.org/abstractairanica/45125

DOI : 10.4000/abstractairanica.45125

ISBN : 1961-960X

ISSN : 1961-960X

Éditeur :

CNRS (UMR 7528 Mondes iraniens et indiens), Éditions de l'IFRI

Référence électronique

Florence Jullien, «David Wilmshurst. Bar Hebraeus. The Ecclesiastical Chronicle», Abstracta Iranica [En ligne], Volume 37-38-39 | 2018, document 29, mis en ligne le 30 décembre 2018, consulté le 26 septembre 2020. URL : http://journals.openedition.org/abstractairanica/45125 ; DOI : https://doi.org/ 10.4000/abstractairanica.45125

Ce document a été généré automatiquement le 26 septembre 2020

Tous droits réservés 


\title{
David Wilmshurst. Bar Hebraeus. The Ecclesiastical Chronicle
}

\author{
Florence Jullien
}

\section{RÉFÉRENCE}

David Wilmshurst. Bar Hebraeus. The Ecclesiastical Chronicle. Gorgias Press LLC, 2016, 594 p. ISBN 978-1-4632-0535-5, (Gorgias Eastern Christian Studies 40)

1 Grigor Abū 'l-Faraj (1226-1286), connu sous son nom syriaque de Bar 'Ebrōyō, fut élu en 1264 "maphrien" de l'Église syro-orthodoxe, la plus haute dignité après le patriarche d'Antioche. Il est considéré comme le dernier grand écrivain de langue syriaque. Fin érudit, il a laissé une œuvre monumentale qui illustre tous les domaines du savoir, et en particulier une "double" chronique, ecclésiastique et profane, qui conserve et compile les données de sources antérieures, parfois perdues. À ce jour, il existait de la Chronique ecclésiastique (ecclesiastikē) une édition du syriaque avec traduction latine publiée en 3 volumes par Jean-Baptiste Abbeloos et Thomas Joseph Lamy entre 1872 et 1877. L'A. nous en donne ici une version anglaise, particulièrement attendue pour mieux faire connaitre cette source incontournable: le texte syriaque de la précédente édition jusqu'ici référente y est reproduit, avec renvoi à la pagination. Cette belle présentation donne ainsi en vis-à-vis le syriaque en pages impaires et la version en anglais sur les pages paires. On pourra s'interroger sur le choix fait par l'A. de conserver le nom latin Bar Hebraeus dans une entreprise de nouvelle traduction du texte; peut-être sera-ce par souci d'une meilleure diffusion de l'ouvrage, le chronographe syriaque étant davantage connu sous son nom latin, en particulier dans les milieux non syriacisants.

2 La Chronique ecclésiastique a pour objet de dresser une histoire des communautés syriaques à travers une succession de biographies des différents patriarches qui siégèrent dans les villes primatiales de l'Orient depuis les temps apostoliques jusqu'à l'époque du rédacteur. Ce type de présentation historique se retrouve surtout dans la tradition historiographique syro-orientale. En élaborant une théorie des successions et 
leur légitimation, Bar 'Ebrōyō a repris une énumération compilée par Jacques d'Édesse et s'est inspiré aussi de plusieurs chroniques antérieures, notamment celle de Michel le Syrien (XII ${ }^{\mathrm{e}}$ siècle), la Chronique jusqu'en 1234, ou l'œuvre de 'Amr ibn Mattaï (XII siècle) en arabe; la rédaction fut poursuivie après la mort du maphrien par son frère, Barsoum, puis par un auteur anonyme jusqu'au $\mathrm{XV}^{\mathrm{e}}$ siècle. David Wilmshurst donne en introduction les éléments biographiques que nous connaissons de la vie et de la carrière de Bar 'Ebrōyō, ainsi que les principaux ouvrages qui lui sont attribués; il y ajoute une intéressante réflexion sur le genre de la Chronique ecclésiastique, entre littérature et histoire ( $\mathrm{p}$. VII-XL).

3 L'organisation générale de l'ouvrage suit la subdivision en deux sections distinctes donnée par le compilateur chroniqueur syriaque. La première (p. 2-309) a trait à la succession des primats du siège antiochéen de l'Église syro-orthodoxe, dans l'espace byzantin, précédée d'une liste des grands prêtres de l'histoire d'Israël depuis Aaron jusqu'aux pontifes de l'époque du Christ, Caïphe et Anne. Puis viennent les différents apôtres et disciples répartis selon les sièges primatiaux de l'Orient (Jérusalem, Éphèse, Alexandrie, Rome, Antioche, Constantinople) (p. 2-16). La continuité apostolique du patriarcat d'Antioche y est détaillée à partir de Pierre, Évode, Ignace, etc. jusqu'à 'Aziz bar Sabtha en 1482 : le texte s'arrête là.

4 La seconde section développe l'historiographie des catholicoi de l'Église syro-orientale dans les territoires à l'est de l'Euphrate (p. 310-505). Pour Bar 'Ebrōyō, lui-même miaphysite, l'Église syro-orthodoxe est la seule légitime : c'est pourquoi il élabore une histoire réinterprétée selon le prisme de ses convictions théologiques, en contestant la légitimité de la continuité apostolique revendiquée par l'Église de l'Est et le siège de Kokhē. L'adoption de la doctrine dyophysite conduisit à une sécession et à une rupture définitive ; cette perception fait alors des métropolites syro-orthodoxes les véritables héritiers des premiers évangélisateurs et leurs continuateurs. Bar 'Ebrōyō attribue à son Église tous les primats du siège de Kokhē antérieurs aux divisions christologiques jusqu'avant Babōy (457-484); il relie ainsi directement - et de façon anachronique - le primat Dadīšō ( $\mathrm{V}^{\mathrm{e}}$ siècle) à l'époque d'Ahudemmeh ( $\mathrm{VI}^{\mathrm{e}}$ siècle, $\mathrm{m}$. en 575$)$, écartant volontairement de sa liste et de la succession apostolique tous les catholicoi ayant œuvré à l'adoption du dyophysisme en Perse. Cette vision orientée de l'histoire faisait du patriarcat syro-oriental un «patrimoine commun des Églises depuis le temps des évangélisateurs ".

5 Deux appendices (p. 507-510; p. 511-513) présentent en listes les noms des différents patriarches syro-orthodoxes depuis l'époque de Sévère jusqu'au $\mathrm{XV}^{\mathrm{e}}$ siècle : patriarches miaphysites d'Antioche (512-1292) ; anti-patriarches; puis patriarches dont le siège a été instauré à Mardin (1293-1493), à Sis (1292-1445), dans le Țūr-'Abdīn (1364-1494); métropolites de Takrīt (559-1059) et maphriens (1075-1507). Une seconde liste donne la succession des catholicoi syro-orientaux subdivisés en évêques de Séleucie-Ctésiphon (280-399), métropolites (399-421) et catholicoi de l'Église de l'Orient (421-1382). Comme le souligne l'A., elles ont été établies à partir des éléments publiés dans le Gorgias Encyclopedic Dictionary of the Syriac Heritage (éd. S. Brock, 2011). Certaines dates ont été révisées et réajustées. On regrettera cependant l'utilisation fréquente du mot "jacobite", à connotation polémique. Une brève sélection bibliographique achève l'ouvrage; il faudrait y ajouter la publication majeure de H. Takahashi, Barhebraeus : A Bio-Bibliography, Piscataway NJ, 2005, ou encore les actes du colloque sur Bar Hebraeus et la Renaissance syriaque (éd. D. Aigle dans un numéro spécial de la revue Parole de l'Orient 
33, 2008 - un seul article est mentionné). On sera gré à l'A. d'avoir inséré un index très utile et plusieurs cartes. Sur les cinq présentées, la troisième, qui concerne l'Église d'Orient (p. 552), est tronquée : il y manque les diocèses du golfe Persique dépendants du Fārs, et ceux du Segestān.

6 La Chronique ecclésiastique fournit non seulement des données intéressant l'histoire des Églises d'Orient et leurs autorités, mais aussi des développements permettant de mieux connaître la diffusion de certains courants de pensée en Syrie, en Mésopotamie, en Babylonie et en Perse, ou les polémiques théologiques post-conciliaires du V $\mathrm{V}^{\mathrm{e}}$ siècle et leur impact durable sur la vie des communautés chrétiennes en Orient.

\section{AUTEURS}

\section{FLORENCE JULLIEN}

CNRS, Mondes iranien et indien, Paris 